\title{
Genetic Diversity of Gaeumannomyces graminis var. tritici Populations Using RAPD and ERIC Markers
}

\author{
Sadeghi $\mathrm{L}^{1}$, Alizadeh $\mathrm{A}^{1}$, Safaie $\mathbf{N}^{1 *}$ and Jamali $\mathrm{SH}^{2}$ \\ ${ }^{1}$ Plant Pathology Department, Tarbiat Modares University, Tehran, Iran \\ ${ }^{2}$ Plant Variety Registration Department, Seed and Plant Certification and Registration Institute, Karaj, Iran
}

\begin{abstract}
Take-all disease which is caused by Gaeumannomyces graminis var. tritici (Ggt) is the most damaging root disease of wheat. Twenty four isolates of pathogen were recovered from diseased samples collected from different provinces of Iran including Fars, Markazi, and Mazandaran. All isolates were specifically identified as Ggt and simultaneously divided into two subpopulations of A and B types. Five primers of RAPD and ERIC primer pair were used to determine the DNA polymorphisms. Cluster analysis was noticed that with the exception of OPC-08 primer, the all remaining RAPD primers and ERIC separated T-28 (having both simple and lobed hyphopodia) from other Ggt isolates with simple hyphopodia. Additionally, these primers identified and separated the two varieties of the pathogen, Gaeumannomyces graminis var. graminis (Ggg) and Ggt. Polymorphism Information Content (PIC) value was estimated between $0.23-0.3$. The tested isolates were divided into three groups including a single member group housed T-28 isolate at $39.5 \%$ similarity. All Ggt isolates with simple hyphopodia can be divided into two groups, the first group from Markazi province with a $12.5 \%$ frequency consisting of three isolates including two B-types (T-1, T-9) that also separated by Principle Component Analysis (PCA). The second group (A-type) contained $83.3 \%$ of the remaining isolates. The Iranian population of Ggt shows a high level of genetic diversity dominated by A-type. The dominant population of Ggt isolates provides the pathogen with the ability to fight or overcome any commonly used control measures such as chemicals or resistant cultivars.
\end{abstract}

Keywords: Gaeumannomyces graminis var. tritici; Genetic diversity; RAPD; ERIC markers

\section{Introduction}

The fungus Gaeumannomyces graminis var. tritici $(G g t)$ is the most important root disease of wheat worldwide tests [1]. Isolates of $G$. graminis var. tritici vary in phenotypic features (colony morphology and pathogenicity) and on the DNA level have been reported previously [2,3]. However, very little research on genetic diversity within populations of G. graminis has been stated [4]. Molecular tools have played a meaningful role in the recent development of specific and rapid identification genome, and considerable polymorphisms were observed among studied isolates. Augustin et al. [5] used RAPD marker to differentiate G. graminis at the intravarietal and intervarietal levels. Lebreton et al. [4] divided $120 \mathrm{Ggt}$ isolates into two groups, $\mathrm{G}_{1}$ and $\mathrm{G}_{2}$, using RAPD and AFLP markers. The aggressiveness of isolates from group $G_{2}$ was significantly greater than those from $G_{1}$ group. Resulting dendrograms from analysis of RAPD data also grouped G. graminis isolates according to their variety identity [6]. In addition, isolates of Ggt were classified as rye-adapted (R) or non-rye-adapted (N) forming distinct groups in dendrograms [7]. On the basis of rDNA analysis using PCR-RFLP method, 144 isolates of Ggt divided into two major groups A and B [8]. Families of short intergenic repeated sequences have been determined in enteric bacteria, primarily Escherichia coli and Salmonella typhimurium. Traditionally REP and ERIC (enterobacterial repetitive intergenic consensus) primers have been used in the analysis of bacterial DNA from a variety of sources including those bacteria that cause plant diseases $[9,10]$. Crozier et al. [11] for the first time used Repetitive Extragenic Palindrome (REP) in fingerprinting Ggt genome, and considerable polymorphisms were observed among studied isolates. Prior to present study, ERIC marker had not been used in evaluating genetic diversity in Ggt population. Knowledge of the genetic structure of pathogen population has important implications for plant breeding and also for fungicide screening programs [12].
Actual damage of take-all disease has not been estimated correctly in Iran, however this disease has been reported as an important wheat disease [13]. Furthermore, this disease has reported as important root disease in the farms of Markazi province and also its dispersion was estimated 12.5, 4.5 and 9.11\% for Shazand, Arak and Khomain, respectively. Despite the importance of this pathogen and economic damage caused annually by the disease on wheat farms, no research on the genetic diversity of its population and identification of Ggt has been taken. The aim of this study is to estimate genetic diversity within Iranian population of Ggt fungus using RAPD and ERIC markers in Iran.

\section{Material and Methods}

\section{Taking sample and fungal isolation}

In the survey conducted in wheat growing seasons, 24 isolates of pathogen were recovered from diseased samples collected from three province of Iran including Fars, Markazi, and Mazandaran. Isolates of Ggt were obtained from diseased pieces root, crown and stem. These pieces were surface-sterilized for $3 \mathrm{~min}$ in sodium hypochlorite, rinsed twice in sterile distilled water, and dried on filter paper under a sterile air flow. They were then placed on Potato Dextrose Agar (PDA) containing streptomycin sulphate $\left(100 \mathrm{mgL}^{-1}\right)$ and rifampicin $\left(50 \mathrm{mgL}^{-1}\right)$,

*Corresponding author: Safaie N, Plant Pathology Department, Tarbiat Modares University, Tehran, Iran, E-mail: nsafaie@modares.ac.ir

Received October 17, 2012; Accepted November 16, 2012; Published November 20, 2012

Citation: Sadeghi L, Alizadeh A, Safaie N, Jamali SH (2012) Genetic Diversity of Gaeumannomyces graminis var. tritici Populations Using RAPD and ERIC Markers. J Plant Pathol Microbiol 3:143. doi:10.4172/2157-7471.1000143

Copyright: $\odot 2012$ Sadeghi L, et al. This is an open-access article distributed under the terms of the Creative Commons Attribution License, which permits unrestricted use, distribution, and reproduction in any medium, provided the original author and source are credited. 
and incubated at $20^{\circ} \mathrm{C}$ for 3-6 days. Cultures resembling G. graminis were then transferred to fresh PDA containing the same antibiotics [1]. Table 1 lists the morphological and pathogenicity characteristics of Ggt isolates used in this study, according to Sadeghi et al. [14].

\section{DNA extraction and marker assay}

Mycelia from 9-day-old cultures grown on liquid medium (5 $\mathrm{g}$ of glucose, $1 \mathrm{~g}$ of yeast extract and $1000 \mathrm{ml}$ distilled water) were collected by vacuum filtration. DNA was extracted according to Safaie et al. [15] DNA concentration and purity was examined using spectrophotometer and by running on $0.8 \%$ agarose gel.

\section{Ggt-specific identification}

Primers Ggt fwd (5'-AAG AAC ATC GGC GGT CTC GCC), Ggt Arev (5'-TAG CGG CTG GAG CCC GCC G) and Ggt Brev2 (5'-CTA CCT GAT CCG AGG TCA ACC TAA GG) were designed by Freeman et al. [8], using $1 \mathrm{x}$ reaction Taq buffer, $1.5 \mathrm{mM} \mathrm{MgCl}, 0.4 \mathrm{mM}$ dNTPs and DNA $50 \mathrm{ng}$. Cycling conditions were 35 cycles of $94^{\circ} \mathrm{C}$ for $30 \mathrm{~s}$, annealing $72^{\circ} \mathrm{C}$ for $1 \mathrm{~min}$ and extension $72^{\circ} \mathrm{C}$ for $1 \mathrm{~min}$, followed by a final extension of $72^{\circ} \mathrm{C}$ for $10 \mathrm{~min}$.

\section{RAPD and ERIC assays}

The RAPD and ERIC-PCR reactions were carried out in $20 \mu \mathrm{l}$ reaction volumes containing $1 \mathrm{x}$ reaction Taq buffer, $1.5 \mathrm{mM} \mathrm{MgCl}$ for RAPD primers and $2 \mathrm{mM} \mathrm{MgCl}$ for ERIC primer, $0.2 \mathrm{mM}$ dNTPs, 1 unit Taq DNA polymerase, $10 \mu \mathrm{M}$ primer (All PCR materials were provided by CinnaGen Co.) and $50 \mathrm{ng}$ fungal DNA. Program PCR for RAPD reactions: an initial denaturation for $2 \mathrm{~min}$ at $94^{\circ} \mathrm{C}$, followed by 35 cycles of denaturation at $94^{\circ} \mathrm{C}$ for $30 \mathrm{~s}$, primer annealing at $36^{\circ} \mathrm{C}$ for $1 \mathrm{~min}$ and extension at $72^{\circ} \mathrm{C}$ for $2 \mathrm{~min}$. The amplification was ended with an additional extension at $72^{\circ} \mathrm{C}$ for $5 \mathrm{~min}$, and program PCR

\begin{tabular}{|c|c|c|c|c|}
\hline No. & Isolate & Province & Hyphopodia & $\begin{array}{c}\text { Pathogenicity level } \\
\text { (Sadeghi et al. [14]) }\end{array}$ \\
\hline 1 & T-1 & Markazi & Simple & Weak \\
\hline 2 & T-3 & Markazi & Simple & Strong \\
\hline 3 & T-4 & Markazi & Simple & Weak \\
\hline 4 & T-7 & Markazi & Simple & Weak \\
\hline 5 & T-9 & Markazi & Simple & Weak \\
\hline 6 & T-10 & Markazi & Simple & Strong \\
\hline 7 & T-11 & Markazi & Simple & Strong \\
\hline 8 & T-19 & Markazi & Simple & Strong \\
\hline 9 & T-22 & Fars & Simple & Strong \\
\hline 10 & T-23 & Fars & Simple & Strong \\
\hline 11 & T-25 & Fars & Simple & Strong \\
\hline 12 & T-26 & Fars & Simple & Strong \\
\hline 13 & T-27 & Fars & Simple & Strong \\
\hline 14 & T-28 & Fars & Lobed \& simple & Weak \\
\hline 15 & T-34 & Mazandaran & Simple & Strong \\
\hline 16 & T-37 & Mazandaran & Simple & Strong \\
\hline 17 & T-38 & Mazandaran & Simple & Weak \\
\hline 18 & T-39 & Mazandaran & Simple & Strong \\
\hline 19 & T-41 & Mazandaran & Simple & Strong \\
\hline 20 & T-42 & Mazandaran & Simple & Strong \\
\hline 21 & T-45 & Mazandaran & Simple & Strong \\
\hline 22 & T-46 & Markazi & Simple & Weak \\
\hline 23 & T-49 & Markazi & Simple & Weak \\
\hline 24 & T-51 & Markazi & Simple & Strong \\
\hline 25 & Ggg & Mazandaran & Lobed & \\
\hline
\end{tabular}

Table 1: Characteristics of Gaeumannomyces graminis var. tritici isolates recovered from wheat in different provinces of Iran.

\begin{tabular}{|l|l|c|l|l|l|}
\hline Factor & Levels & Sample size & \multicolumn{3}{|c|}{$\Phi_{\text {st }}$} \\
\hline Pathogenicity & & \multicolumn{3}{|c|}{$0.06^{*}$} \\
\hline & Weak & 7 & \multicolumn{2}{|c|}{} \\
\hline & Strong & 17 & & & \\
\hline Province & & & & & \\
\hline & Markazi & 11 & & Markazi & Fars \\
\hline & Fars & 6 & Fars & $0.073^{*}$ & \\
\hline & Mazandaran & 7 & Mazandaran & $0.031 \mathrm{~ns}$ & $0.033^{\text {ns }}$ \\
\hline
\end{tabular}

*: Significant at 0.05 level; ns: non-significant

Table 2: Analysis of molecular variance (AMOVA) of two factors on molecular data matrix. $\Phi_{\text {st }}$ values correspond to the fraction of the molecular diversity accounted by the factor. The significance of the values was calculated using 999 permutations on data sets.

for ERIC reaction: the first cycle at $95^{\circ} \mathrm{C}$ for 2 min was followed by 35 cycles at $94^{\circ} \mathrm{C}$ for $1 \mathrm{~min}$, at $45.5^{\circ} \mathrm{C}$ for $1 \mathrm{~min}$, and at $72^{\circ} \mathrm{C}$ for $1: 30$ min; 1 cycle at $72^{\circ} \mathrm{C}$ for $8 \mathrm{~min}$. [11,12,16]. Amplification reactions of specific PCR, RAPD and ERIC were performed using an Eppendorf thermocycler (Eppendorf Mastercycler Gradient, Germany). In order to check the reproducibility of all markers, PCR was repeated twice for all 24 samples. PCR products for RAPD, ERIC and specific primers were separated by electrophoresis in $1.5 \%$ agarose gels with $1 \mathrm{x}$ TBE buffer and visualized under UV light following ethidium bromide staining and photographed. A $1 \mathrm{~Kb}$ and $100 \mathrm{bp}$ for DNA ladder were used as size marker in gels.

\section{Statistical analysis}

The comparison of each profile for each primer was performed on the basis of the presence (1) and absence (0) of the same length bands. Each band was assumed to represent a single genetic locus. The resulting data matrices were used for cluster analysis of isolates by the UPGMA algorithm and Jaccard's similarity coefficient by NTSYSpc software version 2.02 [17]. The resulting data matrices were used and the discrimination power of each marker was evaluated by the Polymorphism Information Content (PIC) [3] as $\mathrm{PIC}=1-\sum_{i=1}^{\mathrm{n}} \mathrm{P}_{i}^{2}$, where $\mathrm{p}$ is the frequency of the each band. Moreover, the distinguishing power of each marker was described by the Resolving Power (Rp) index as $R_{p}=\sum I_{b}$, in which $\mathrm{I}_{\mathrm{b}}$ is the "band in formativeness" of each marker. In this formula, $\mathrm{I}_{\mathrm{b}}$ is calculated by $I_{b}=1-(2 \times|0.5-p|$, where $\mathrm{p}$ is the proportion of the 24 isolates containing the band [18]. The structure of the genetic diversity of the isolates was tested by analysis of molecular variance (AMOVA) [19]. This method provides an estimate of the fraction of between-population diversity (i.e. $\Phi$ st), analogous to the Fst [20], which can be tested by a permutational procedure. In this study, AMOVA was performed to test the structure (i) among weak and strong isolates in terms of their pathogenicity, and (ii) among locations (provinces) of isolates were their samples are taken. The structure of the genetic diversity was further analyzed by a principal component analysis (PCA) from the Nei's genetic distance matrix. AMOVA and PCA analyses were performed with Gen Alex software version 6.3 [21]. Sequence of primers tested with RAPD and ERIC markers are presented in table 2 .

\section{Results, Discussion and Conclusion}

Take-all of wheat caused by the fungus Gaeumannomyces graminis var. tritici $(G g t)$ is the most significant root disease of wheat throughout the world. The same pathogen also affects triticale, barley and rye, but to lesser extents [1,22-24]. Twenty four isolates of $G g t$ were recovered from infection samples of pathogen collected from different provinces of Iran including Fars, Markazi and Mazandaran. This disease has been recognized for more than 30 years ago in Iran 
Citation: Sadeghi L, Alizadeh A, Safaie N, Jamali SH (2012) Genetic Diversity of Gaeumannomyces graminis var. tritici Populations Using RAPD and ERIC Markers. J Plant Pathol Microbiol 3:143. doi:10.4172/2157-7471.1000143

Page 3 of 5

\begin{tabular}{|c|c|c|c|c|c|c|c|}
\hline Primer & Sequence primer ( $\left.5^{\prime}-3^{\prime}\right)$ & $\begin{array}{l}\text { No. of } \\
\text { bands }\end{array}$ & $\begin{array}{l}\text { No. of polymorphic } \\
\text { bands }\end{array}$ & $\begin{array}{c}\text { Percentage } \\
\text { polymorphism }\end{array}$ & PIC & $\mathrm{Rp}$ & $\begin{array}{l}\text { Size range of } \\
\text { bands (bp) }\end{array}$ \\
\hline OPC-08 & CCC GTC AGC A & 17 & 17 & 100 & 0.28 & 9 & $4000-250$ \\
\hline OPC-19 & GTA GAC CCG T & 38 & 32 & 84.21 & 0.23 & 10.58 & $5000-230$ \\
\hline Cs1503 & TGG ACC GGT G & 29 & 28 & 96.55 & 0.29 & 15.58 & $3086-290$ \\
\hline P5 & GAG TGG TGA C & 28 & 28 & 100 & 0.3 & 13 & $4643-334$ \\
\hline P6 & CGG CCC ACG T & 19 & 19 & 100 & 0.3 & 7.75 & $3640-188$ \\
\hline ERIC & $\begin{array}{c}\text { Rl- } \\
\text { CACTTAGGGGTCCTCAATGT } \\
\text { I2-AAGTAAGTGACTGTGAGCG }\end{array}$ & 31 & 26 & 83.87 & 0.25 & 8.5 & $2370-250$ \\
\hline
\end{tabular}

Table 3: Names and sequences of tested primers, for RAPD and ERIC markers.

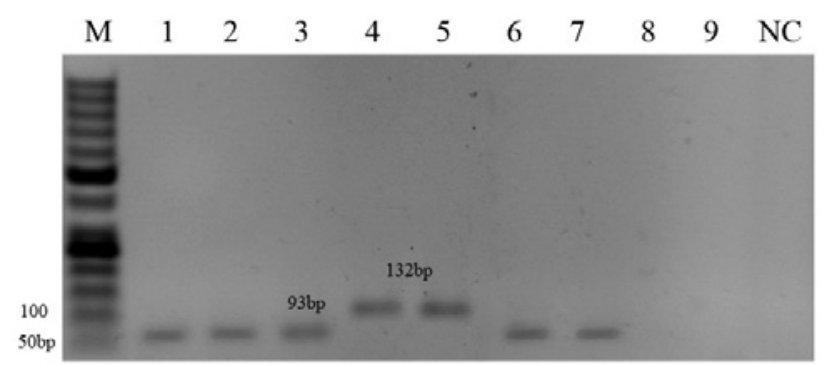

Figure 1: Specific identification of representation isolates Gaeumannomyces graminis var. tritici lanes 1, 2, 3, 6, 7 amplified fragments 93 bp as A type and lanes 4, 5 amplified 132 bp B type. Lane 8 and 9 were Gaeumannomyces graminis var. graminis and Magnaportae grisea, respectively: no amplified fragment. M Gene ruler: 50 bp DNA Ladder. NC: Negative Control.
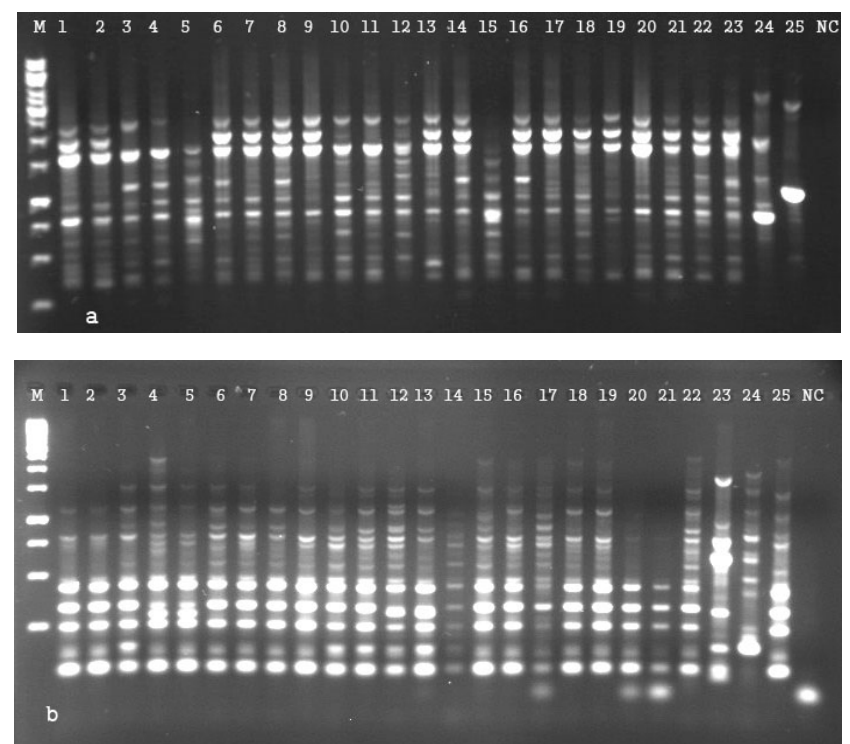

Figure 2: Banding patterns of (a) P5 and (b) ERIC primed polymerase chain reaction-amplified genomic DNA of 24 Gaeumannomyces graminis var. tritici and Gaeumannomyces graminis var. graminis isolates (lanes 1-25: T-3, T-4 T-7, T-1, T-9, T-10, T-11, T-19, T-22, T-23, T-25, T-26, T-27, T-34, T-37, T-38 T-39, T-41, T-42, T-45, T-46, T-49, T-51, T-28 and Ggg). Lane 26: Negative control; lane M: Gene ruler 1 kb DNA Ladder.

[22] and since then reported from different regions including Golestan, Hamedan, Ghazvin, Markazi, Fars, Khuzestan, Tehran and Kurdistan provinces [13]. According earlier study, the results of pathogenicity assays showed that, all Ggt isolates were pathogenic on wheat and nine of them were pathogenic on oat as well [14]. Statistical analyses of the pathogenicity assay indicated virulence among isolates were significantly different. Previous studies had displayed considerable variation in virulence among $G g t$ isolates $[11,25,26]$. Some Ggt isolates found in Australia reported to be capable of causing disease on oats [7]. All isolates identified with specific primers of Ggt for rapid and confident identification. One isolate of Ggg and Magnaportae grisea did not amplify any fragment. Two isolates T-1, T-9 of Ggt, amplified fragment 132 bp as B type, and remainder of Ggt isolates, amplified fragment $93 \mathrm{bp}$ as A type, where only five representative isolates of this type (Figure 1) are taken for specific identification of representation isolates of Gaeumannomyces graminis var. tritici. For investigation of genetic diversity, five primers of RAPD and one pair of ERIC primers were used to determine the DNA polymorphisms for 24 isolates of $\mathrm{Ggt}$ and one isolate of $\mathrm{Ggg}$ (Figure 2, Table 3). The results of cluster analysis showed that with the exception of OPC-08 primer, the remaining all RAPD primers and ERIC separated T-28 (having lobed hyphopodia) from other Ggt isolates with simple hyphopodia. Additionally, these primers identified and readily separated the two varieties of pathogen, Ggg and Ggt. At 39.5\% similarity, the tested isolates were divided into three groups including a single member group of T-28 isolate and rest of Ggt isolates with simple hyphopodia divided into two groups, the first group was belonged to Markazi province with a $12.5 \%$ frequency consisting of three isolates including T-1, T-7, T-9 while the second group contained $84 \%$ of the remaining isolates (Figure 3). Cluster analysis for combined RAPD-PCR and ERIC data separated the isolates with simple hyphopodia into two main groups. Association among the isolates revealed by PCA was represented in figure 4 . The first three components explained about $65 \%$ of the total variation, with 32.83 , 16.45 , and $15.25 \%$ for the first, the second, and the third components, respectively. Different pathogenicity levels of isolates did account for $6 \%$ of the total variation revealed by AMOVA analysis (Table 2). The population pair-wise F-statistics matrix between weak and strong pathogenic isolates was significant at 0.05 (999 permutations). In graphical representation showed by PCA, the weak isolates were more spread along the first and two components (axis 1 vs. axis 2), i.e. had a higher genetic diversity, compared with isolates with strong pathogenicity. On second structure, $5 \%$ of the total variation was observed between three locations (provinces) of taken samples. T-1 and T-9 and lobed hyphopodium isolate (T-28) separated from other isolates by principle component analysis. The F-statistic was significant at 0.05 between Fars and Markazi provinces (Table 2). These two groups were relatively separated by the second and third components (axis 2 vs. axis 3 ) as is shown in figure $4 \mathrm{~b}$.

A total of 140 polymorphic fragments were detected at the 6 RAPD and ERIC markers with an average number of 17 to 28 per RAPD primers and 26 polymorphic for ERIC primer and polymorphism information content (PIC) value varied between 0.23-0.3. (Table 2). Weber et al. [12] used five RAPD primers to evaluate genetic 


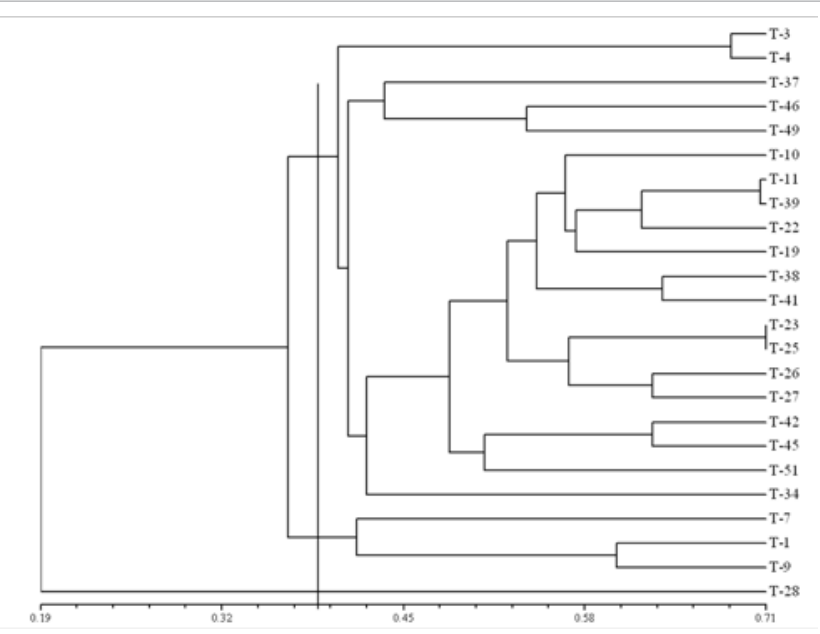

Figure 3: Dendrogram showing genetic relationshipsamong 24 Gaeumannomyces graminis var. tritici based on combined data for the 5 RAPD and one pair ERIC primers. Cluster analysis was performed by the UPGMA method on a Jaccard's similarity matrix.

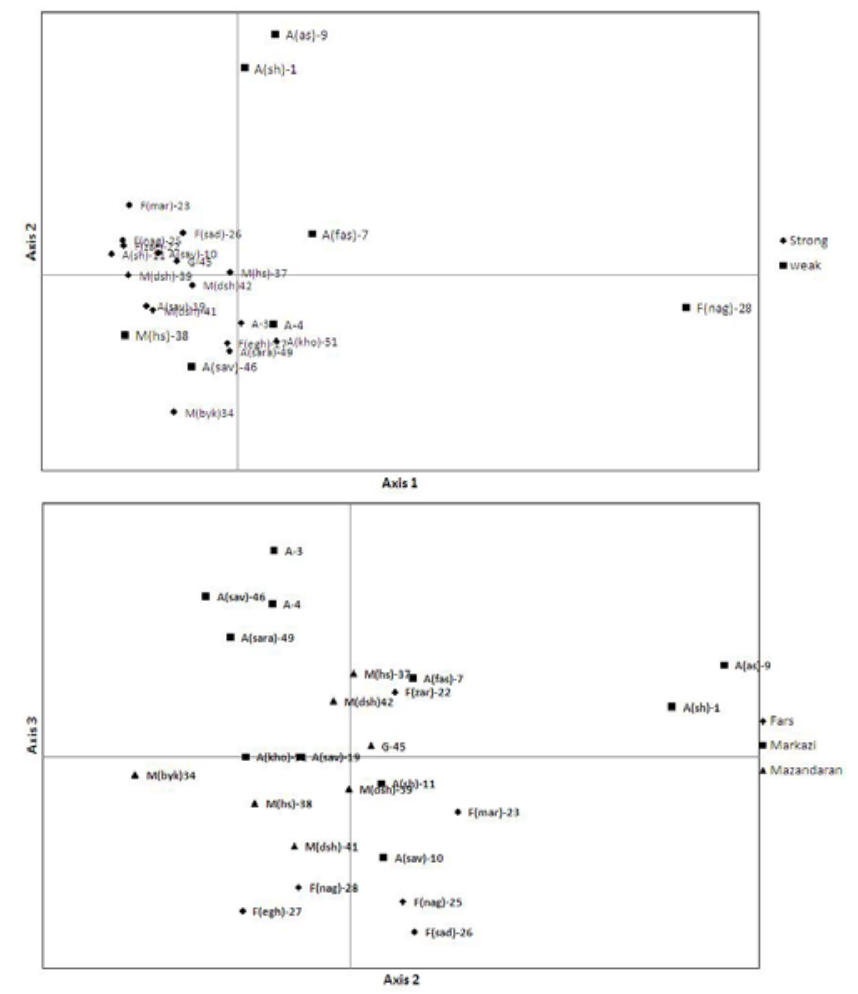

Figure 4: Genetic relationships depicted among 24 Gaeumannomyces graminis var. tritici isolates by the first and second axes (4a), and the second and third axes (4b) for two grouping structures (pathogenicity and locations of samples) derived from a principal component's analysis on the RAPD and ERIC data.

variability among 70 isolates and related them to sensitivity to silthiofam fungicide. RAPD analysis suggested a high level of genetic variation and identified two groups at the $54 \%$ similarity level. Studies of Freeman et al. [8] based on the polymorphisms in ITS2, identified 144 isolates of Ggt as A- or B-type and were all tested for sensitivity to Silthiofam. There was a highly significant correlation between B type isolates. Also sensitivity to Silthiofam was demonstrated in a collection of 358 Ggt populations in winter wheat. This may be important in order to pathogen populations with high genetic variation that are potentially proficient of rapidly evolving responses to changing environmental conditions [27]. Consequently, it could be difficult to find longlasting effective fungicide against this kind of pathogen. In our results, majority of isolates was related to one group that belong to A type. Also according to previous study by Sadeghi et al. [14], comparison pathogenicity resulting with the molecular showed the weaker virulence by the first group while the second group comprising $84 \%$ of isolates, explained over $65 \%$ disease severity. Also all nine isolates pathogenic on oat belonged to the second group. These results indicated that the dominant population of $G g t$ isolates provides the pathogen with the ability to fight or overcome any commonly used control measures such as chemical or resistant cultivars. Similar divisions of take-all fungus populations into two main groups based on our data were observed that have been reported by other researchers. Augustin et al. [5] used RAPD markers to differentiate G. graminis at the intravarietal and intervarietal levels. After amplifying with OPB-07 primer, Ggt isolates were separated into two main groups $\mathrm{A} 1$ and $\mathrm{A} 2$ with different banding pattern. The same researchers disclosed that colonies of subgroup A1 produced dense, darkly pigmented aerial mycelium and those of subgroup A2 had only little aerial mycelium ranging from light grey to dark grey $[12,16]$. In these groups, the average mycelial linear growth is different from one another. Furthermore researches of Bateman et al. [2] used a mitochondrial rDNA probe distinguished two groups of the pathogen associated with different host-crop species. Also Lebreton et al. [4] examined $120 \mathrm{Ggt}$ isolates using RAPD and AFLP markers and separated them into two groups, G1 and G2. The aggressiveness of isolates from group G2 was significantly greater than those from G1 group. In this study, oat attaching isolates which belonged to second group also were more aggressive.

Some fungal genomes have been examined with REP primers $[11,28]$. Edel et al. [29] showed that using REP primers polymorphism among isolates of Fusarium oxysporum can be well revealed. Crozier et al. [11] for the first time used REP primers for the fingerprinting of this pathogen which exhibited valuable polymorphisms among isolates tested. RAPD markers are useful tools especially for fungi that are obligate parasites or that have a population structure composed of clonal lineages and as advanced PCR-based markers turn in to available, it may become possible to amplify specific DNA sequences from soil or root samples and make a direct assessment of the genetic structure of populations of soil borne fungi without first making pure cultures [27]. Using this marker as fast and easy method can be a powerful tool for investigating the occurrence and distribution of this pathogen as well as studying changes in the populations of subgroups of G. graminis in cereal cropping systems. Moreover, molecular and pathogenicity test results confirmed studies of the other researchers $[14,23]$ and demonstrated that population of $G g t$ in the wheat growing regions of Iran are highly virulent and also showed that over $80 \%$ of isolates examined belong to second group (A-type) which were more aggressive than the first group. In this study with RAPD and ERIC markers, moreover, two isolates of B- type were discernible at other Ggt isolate. T-28 isolate with lobed hyphopodium and Ggg isolate were detectable at other Ggt isolates.

\section{Acknowledgment}

The authors thank Mr. F. Khazaee for reading the draft of the article.

\section{References}

1. Hornby D, Bateman GL (1998) Take-All disease of cereals: a regional perspective. CAB International, Madison.

2. Bateman GL, Ward E, Hornby D, Gutteridge RJ (1997) Comparisons of isolates 
Citation: Sadeghi L, Alizadeh A, Safaie N, Jamali SH (2012) Genetic Diversity of Gaeumannomyces graminis var. tritici Populations Using RAPD and ERIC Markers. J Plant Pathol Microbiol 3:143. doi:10.4172/2157-7471.1000143

of the take-all fungus, Gaeumannomyces graminis var. tritici, from different cereal sequences using DNA probes and non-molecular methods. Soil Biol Biochem 29: 1225-1232.

3. Anderson JA, Churchill GA, Autrique JE, Tanksley SD, Sorrells ME (1993) Optimizing parental selection for genetic linkage maps. Genome 36: 181-186.

4. Lebreton L, Lucas P, Dugas F, Guillerm AY, Schoeny A, et al. (2004) Changes in population structure of the soilborne fungus, Gaeumannomyces graminis var. tritici during continuous wheat cropping. Environ Microbiol 6: 1174-1185.

5. Augustin C, Ulrich K, Ward E, Werner A (1999) RAPD-based inter- and intravarietal classification of fungi of the Gaeumannomyces-Phialophora complex. Journal of Phytopathology 147: 109-117.

6. Bryan GT, Labourdette E, Melton RE, Nicholson P, Daniels MJ, et al. (1999) DNA polymorphism and host range in the take-all fungus, Gaeumannomyces graminis. Mycol Res 103: 319-327.

7. Bryan GT, Daniels MJ, Osbourn AE (1995) Comparison of fungi within the Gaeumannomyces-Phialophora complex by analysis of ribosomal DNA sequences. Appl Environ Microbiol 61: 681-689.

8. Freeman J, Ward E, Gutteridge RJ, Bateman GL (2005) Methods for studying population structure, including sensitivity to the fungicide silthiofam, of the cereal take-all fungus, Gaeumannomyces graminis var. tritici. Plant Pathology 54: 686-698

9. Tymon AM, Pell JK (2005) ISSR, ERIC and RAPD techniques to detect genetic diversity in the aphid pathogen Pandora neoaphidis. Mycological Research 109: 285-293.

10. Versalovic J, Koeuth T, Lupski JR (1991) Distribution of repetitive DNA sequences in eubacteria and application to fingerprinting of bacterial genomes. Nucleic Acids Res 19: 6823-6831.

11. Crozier JB (1999) Evaluation of agents for the suppression of take-all of wheat in Virginia in greenhouse and field studies, and characterization of isolates of Gaeumannomyces graminis varieties. PhD Dissertation. Virginia Polytechnic Institute and State University, Blacksburg, VA, USA.

12. Weber Z, Irzykowska L, Bocianowski J (2005) Analysis of mycelial growth rates and RAPD-PCR profiles in a population of Gaeumannomyces graminis var. tritici originating from wheat plants grown from Fungicide-treated seed. Journal of Phytopathology 153: 318-324.

13. Galandar M (2000) An evaluation and dispersion determine of take-all disease in Markazi province. MS thesis, plant pathology, College of Agriculture Mashhad University.

14. Sadeghi L, Alizadeh A, Safaie N, Ghalandar M (2010) Identification of Iranian populations of Gaeumannomyces graminis var. tritici using morphological, molecular and pathological studies. Iran J Plant Path 45: 27-30.

15. Safaei N, Alizadeh AA, Saeidi A, Adam G, Rahimian H (2005) Molecula characterization and genetic diversity among Iranian populations of Fusarium graminearum, the causal agent of wheat headblight. Iran J Plant Path 41: 171189

16. Ulrich K, Augustin C, Werner A (2001) Genetic classification of isolates of the Gaeumannomyces-Phialophora complex in relation to phenotypic characteristics. Proceeding of $5^{\text {th }}$ Congress European Foundation for Plant Pathology, Toaormina -Giardini Naxos, Italy.

17. Rohlf FJ (1998) NTSYSpc Numerical Taxonomy and Multivariate Analysis System, Version 2.1. Exeter Software, New York.

18. Prevost A, Wilkinson MJ (1999) A new system of comparing PCR primers applied to ISSR fingerprinting of potato cultivars. Theor Appl Genet 98: 107112.

19. Excoffier L, Smouse PE, Quattro JM (1992) Analysis of molecular variance inferred from metric distances among DNA haplotypes: application to human mitochondrial DNA restriction data. Genetics 131: 479-491.

20. Peakall R, Smouse PE (2006) GENALEX 6: genetic analysis in Excel. Population genetic software for teaching and research. Mol Ecol Notes 6: 288295.

21. Wright S (1949) The genetical structure of populations. Ann Eugen 1: 323-334

22. Asher MJC, Shipton PJ (1981) Biology and control of take-all. Academic Press New York

23. Freeman J, Ward E (2004) Gaeumannomyces graminis, the take-all fungus and its relatives. Mol Plant Pathol 5: 235-252.

24. Walker J (1973) Gaeumannomyces graminis var. avenae var. tritici-CMl Description of fungi and bacteria. No. 381, 382 and 383 respectively.

25. Asher MJC (1980) Variation in pathogenicity and cultural characters in Gaeumannomyces graminis var. tritici. Transactions of the British Mycological Society $75: 213-220$

26. Dewan MM, Sivasithamparam K (1989) Differences in the pathogenicity of isolates of take-all fungus from roots of wheat and ryegrass. Soil Biol Biochem 22: $119-122$

27. McDonald BA, Miles J, Nelson LR, Pettway RE (1994) Genetic variability in nuclear DNA in field population of Stagonospora nodorum. Phytopathology 84 250-255.

28. George ML, Nelson RJ, Zeigler RS, Leung H (1998) Rapid population analysis of Magnaporthe grisea by using rep-PCR and endogenous repetitive DNA sequences. Phytopathology 88: 223-229.

29. Edel V, Steinberg C, Avelange I, Laguerre G, Alabouvette C (1995) Comparison of three molecular methods for the characterization of Fusarium oxysporum strains. Phytopathology 85: 579-585. 